\title{
Aqueous Synthesis of CdTe Quantum Dot Using Dithiol-Functionalized Ionic Liquid
}

\author{
Suk Young Choi, ${ }^{1}$ Jong Pil Shim, ${ }^{1}$ Dong Sun Kim, ${ }^{1}$ TaeYoung Kim, ${ }^{2}$ and Kwang S. Suh ${ }^{1}$ \\ ${ }^{1}$ Department of Materials Science and Engineering, Korea University, 5-1 Anam-dong, Seongbuk-gu, Seoul 136-713, Republic of Korea \\ ${ }^{2}$ Electronic Materials and Device Research Center, Korea Electronics Technology Institute, Gyeonggi-do 463-816, Republic of Korea
}

Correspondence should be addressed to Kwang S. Suh, suhkwang@korea.ac.kr

Received 6 August 2011; Accepted 28 October 2011

Academic Editor: Somchai Thongtem

Copyright ( 12012 Suk Young Choi et al. This is an open access article distributed under the Creative Commons Attribution License, which permits unrestricted use, distribution, and reproduction in any medium, provided the original work is properly cited.

\begin{abstract}
We report on an aqueous synthesis of cadmium telluride (CdTe) nanocrystals by using dithiol-functionalized ionic liquids (dTFILs). The dTFILs were designed to have dithiol and vinylimidazolium functional groups and used as a ligand molecule of CdTe quantum dot (QD) to utilize the bidendate chelate interaction afforded by the dithiol groups of dTFILs. The photoluminescence quantum yield of dTFIL-capped CdTe QDs reached up to $\sim 40 \%$, and their luminescent property was maintained for 8 weeks, suggesting an improved stability in water phase. This approach will provide a new synthetic route to the water soluble QDs.
\end{abstract}

\section{Introduction}

Quantum dots (QDs) have been a topic of intense theoretical and experimental investigation owing to their size-tunable luminescence, narrow photoluminescence (PL) bands, and broad absorption spectra [1-4]. QDs are often prepared from organometallic precursors via high-temperature solution routes, in which their inorganic core is capped with organic ligand mixtures consisting of trioctylphosphine/trioctylphosphine oxide (TOP/TOPO) and/or long-chain alkylamines [5-8]. Substitution of these organic ligands with polarterminated groups permits tailoring of QDs for efficient dispersal in aqueous solution, which makes them compatible with biological manipulation [9-12]. The QDs in an aqueous environment have been achieved with various methods including silica shelling [13-16], micelle formation around the external organic capping layer $[17,18]$, and formation of polymer coatings [19-21]. While many of the reported schemes render aqueous solubility of QDs, they often have several limitations which include short-term stability and increased nanoparticle diameter from 2-5 nm to 20-100 nm [22-24]. These limitations underscore the need for developing new approaches for surface functionalization of QDs to improve their stability in water phase without increasing its size drastically.
In this regard, the direct synthesis of QDs in water phase provides an attractive alternative because of its simplicity and use of relatively soft condition [25-27]. Prior reports showed that cadmium telluride (CdTe) QDs with moderately high photoluminescence quantum efficiency $(\mathrm{QE})$ have been produced via aqueous synthetic route with a thiol capping ligands such as mercaptocarbonic acid, 2-aminoethanethiol, and dihydrolipoic acid [28-30]. However, the environmental instability of QDs prepared by aqueous synthetic method was also reported. Therefore, an improvement of the stability of CdTe QDs in water is a task of special interest.

In parallel, ionic liquids (ILs) have recently led to a growing interest in the preparation of organic or inorganic nanomaterials because of their unique properties that can be tuned by selecting appropriate combination of cations and anions [31-33]. ILs have been reported to effectively stabilize a range of colloidal nanocrystals in solutions with controlled hydrophilic or hydrophobic surface properties. Therefore, the QD-ionic liquid hybrids are expected to be one of the most promising materials $[34,35]$. This study intends to provide a direct aqueous synthetic route to the CdTe QDs capped with ionic liquid. The role of the ILs on the stability and emission properties of QDs in the aqueous solution is also investigated. To this end, we designed a dith iol-functionalized ionic liquid consisting of dithiol and 
<smiles>C=Cn1ccnc1</smiles><smiles>C=C[n+]1ccn(CC(COC(=O)CS)OC(=O)CS)c1</smiles>

Dithiol-functionalized ILs (dTFIL)

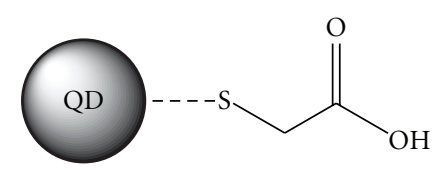

MAA-capped CdTe QDs

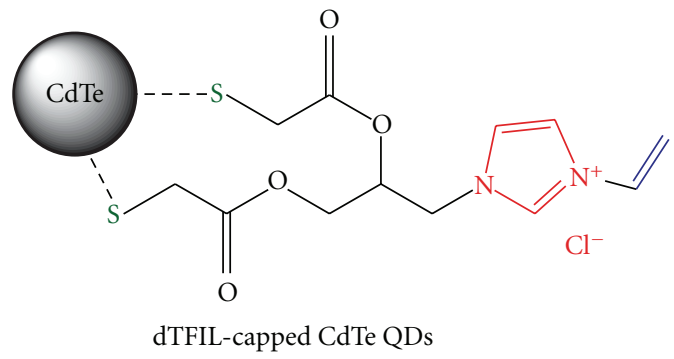

Scheme 1: Synthetic route to the dithiol-functionalized ionic liquid (dTFIL).

vinylimidazolium coupled with chloride, as illustrated in Scheme 1. This approach utilizes the bidendate chelate interaction afforded by the dithiol groups of IL, while the hydrophilic vinylimidazolium groups provide solubility in water as well as possible postpolymerization reaction. This new ligand allows for the design of QDs that are water compatible, stable, and multifunctional.

\section{Experimental}

CdTe QDs were synthesized via aqueous synthetic route in which $\mathrm{Cd}^{2+}$ ions and NaHTe were reacted in the presence of dithiol-functionalized ionic liquid (dTFIL). The control experiment with the use of mercaptoacetic acid (MAA) as a capping ligand was also conducted for comparison.

\subsection{Synthesis of Dithiol-Functionalized Ionic Liquid (dTFIL).} The preparation of thiol-functionalized ionic liquid was as follows: 1-(2', $3^{\prime}$-dihydroxypropyl $)-3$-vinylimidazolium chloride (1) was prepared from the reaction of 1-vinylimidazole and 3-chloro-1,2-propanediol at $80^{\circ} \mathrm{C}$ for $72 \mathrm{~h}$ under $\mathrm{N}_{2}$ atmosphere. A mixture containing $0.1 \mathrm{~mol}$ of $1-\left(2^{\prime}, 3^{\prime}-\right.$ dihydroxypropyl)-3-vinyl imidazolium chloride (1) and
$0.3 \mathrm{~mol}$ of mercaptoacetic acid (MAA) was refluxed with $0.03 \mathrm{~mol}$ of $p$-toluenesulfonic acid in toluene. After the solvent was evaporated in a rotary evaporator, $1,3-\mathrm{di}\left(2^{\prime}, 3^{\prime} \mathrm{di}-\right.$ mercaptoacetoxypropyl)vinyl imidazolium chloride (dTFIL) (2) was obtained by washing with $\mathrm{CH}_{2} \mathrm{Cl}_{2}$.

2.2. Aqueous Synthesis of dTFIL-Capped CdTe QD. CdTe QDs were synthesized by the reaction of oxygen-free $\mathrm{NaHTe}$ with $\mathrm{N}_{2}$-saturated $\mathrm{Cd}\left(\mathrm{ClO}_{4}\right)_{2} \cdot 6 \mathrm{H}_{2} \mathrm{O}$ in the presence of dTFIL or MAA. The NaHTe solution was prepared by reducing metallic tellurium powder $(0.383 \mathrm{~g}, 3 \mathrm{mmol}$ in $10 \mathrm{~mL}$ water) with sodium borohydride $(0.227 \mathrm{~g}, 6 \mathrm{mmol}$ in $5 \mathrm{~mL}$ water) at $0^{\circ} \mathrm{C}$. A solution of $\mathrm{Cd}\left(\mathrm{ClO}_{4}\right)_{2} \cdot 6 \mathrm{H}_{2} \mathrm{O}(1.97 \mathrm{~g}$, $4.7 \mathrm{mmol}$ ) and dTFILs (or MAA) $(7 \mathrm{mmol})$ in $250 \mathrm{~mL}$ of demineralized water was adjusted to $\mathrm{pH} 11$ with $1 \mathrm{M} \mathrm{NaOH}$. The solution was placed in a three-necked flask and deaerated with $\mathrm{N}_{2}$ bubbling for 30 min. After NaHTe solution was injected, the reaction mixture was refluxed for 24 hours and then cooled down to room temperature.

2.3. Characterization. UV-vis absorption spectra were recorded at room temperature using a Shimadzu UV-3101PC spectrophotometer, and photoluminescence measurements were performed at room temperature using an AMINCO 


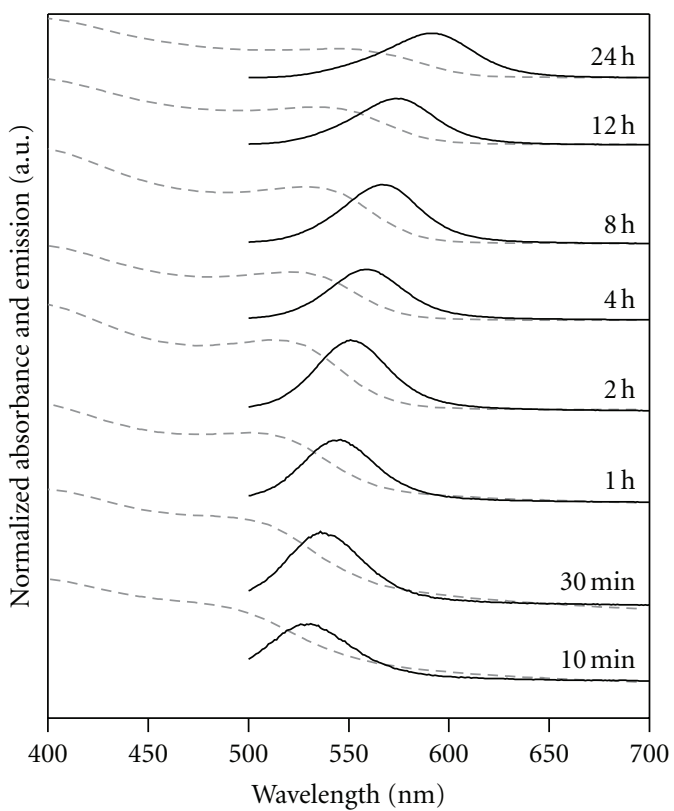

FIgURE 1: Absorption and photoluminescence spectra of IL-capped CdTe QDs with respect to the reaction time. PL spectra were recorded with an excitation at $470 \mathrm{~nm}$.

BOWMAN II Luminescence spectrometer. Quantum efficiencies (QEs) of all samples were estimated by using Rhodamine $6 \mathrm{G}$ as a reference. The $\mathrm{QE}$ was obtained by comparing the integrated PL intensities of the CdTe QDs to Rhodamine 6G, while optical densities of sample and reference were set to the same value $(<0.15)$ to avoid significant reabsorption. High-resolution transmission electron microscope (HRTEM) images were obtained on a JEOL JEM-2000EX operated at $200 \mathrm{kV}$. The samples for TEM studies were prepared by dropping diluted aqueous solution of CdTe QDs onto 400 mesh carbon-coated copper grids. The size distribution of QDs in aqueous solution was measured by a dynamic light scattering (DLS) instrument (Microtrac NPA252) equipped with a $780 \mathrm{~nm}$ laser.

\section{Result and Discussion}

Figure 1 shows the absorption and PL spectra of the dTFILcapped CdTe QDs in aqueous solution. As expected for quantum-sized particles, the position of the first electronic transition was shifted to higher photon energies in accordance with the size quantization effect. The PL emission peak position of QDs shifts from 529 (green) to $593 \mathrm{~nm}$ (orange) with an increase of the QD size. The whole spectra between these two wavelengths is covered by the intermediate sizes of CdTe QDs. The full width at half maximum (FWHM) is about $35 \mathrm{~nm}$ at the emission wavelength of $529 \mathrm{~nm}$, which is close to the previously reported values [25-27]. The values of FWHM increase from 35 to $55 \mathrm{~nm}$ with increasing QD size and this is ascribed to the effect of Ostwald ripening and the wider size distribution of CdTe QDs in the aqueous solution [28-30].
The photoemission quantum yields were calculated using Rhodamine 6G (in ethanol, QY $=0.95$ ). For the measurement, concentration was adjusted in a way that both reference and QD samples showed same optical densities at the excitation wavelength, and solvent refractive indexes were taken into account. The photoluminescence quantum yield of dTFIL-capped CdTe QD ranged up to $40 \%$, comparable to the value reported in previous literatures [25-30].

Figure 2 shows the typical photographs of the dTFILcapped CdTe QDs in aqueous solution, which were obtained from the same sample at different reaction times. The wellresolved lattice fringes for the as-synthesized QD were observed with high-resolution transmission electron microscope (HRTEM), indicating a formation of crystalline structure of CdTe QD. The TEM studies also reveal that the size of dTFIL-QD (at $12 \mathrm{~h}$ reaction time) is $5 \pm 0.5 \mathrm{~nm}$, while the hydrodynamic size of dTFIL-QD was measured as $\sim 7 \mathrm{~nm}$ by dynamic light scattering (DLS). This result implies that dTFIL molecules bind to the surface of CdTe QDs with a capping thickness of $\sim 1 \mathrm{~nm}$, which is close to the estimated value from molecular simulation of dTFIL.

On the other hand, the stability of CdTe QD in aqueous solution is strongly dependent on the nature of the capped ligands. The dTFIL-capped QDs were stable in aqueous solution for at least 8 weeks, whereas MAA-capped QD were stable only for 2-3 weeks. Figure 3 gives a comparison of PL spectra for MAA-capped and IL-capped QDs in water after the 15 days of standing at room temperature. While the MAA-capped QDs undergo a significant decrease in emission peak maxima with a slight redshift in the peak position, dTFIL-capped QDs maintain their initial PL intensities. This is indicative of the capability of dTFIL ligand to effectively stabilize the QDs in the water phase and thus prevent their uncontrolled growth. Moreover, a slight enhancement in emission intensity was also observed for dTFIL-capped QDs, which is attributed to the specific suppression of quenching process by dTFILs. For MAA-capped QDs, MAAs are likely to dissociate from the QD surface as thiol group is converted into disulfide with the formation of localized electronic surface states and gradual precipitation of the QDs $[28,36]$. In contrast, bidendate thiol groups of dTFILs lead to the efficient protection of QD, because they have the stronger coordinative ability with CdTe QD surface due to the multiple binding sites. These effects may contribute to the enhanced stability and the relatively high quantum yield of CdTe QD in water.

\section{Conclusion}

In summary, we have demonstrated an effective method for aqueous synthesis of highly luminescent and stable CdTe nanocrystal by using thiol-functionalized ionic liquid as ligand molecules. The photoluminescence quantum yield of dTFIL-capped CdTe nanocrystals reached up to $\sim 40 \%$. The luminescent property was maintained for 8 weeks with an improved stability. This approach will provide a new synthetic route to the functionalized QDs in water phase. 


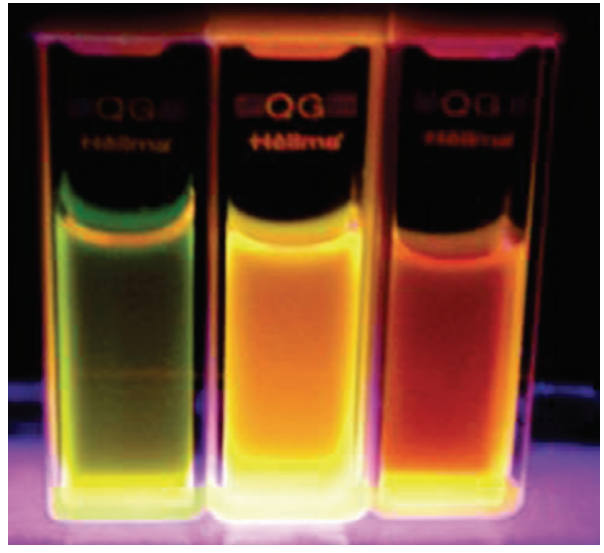

(a)

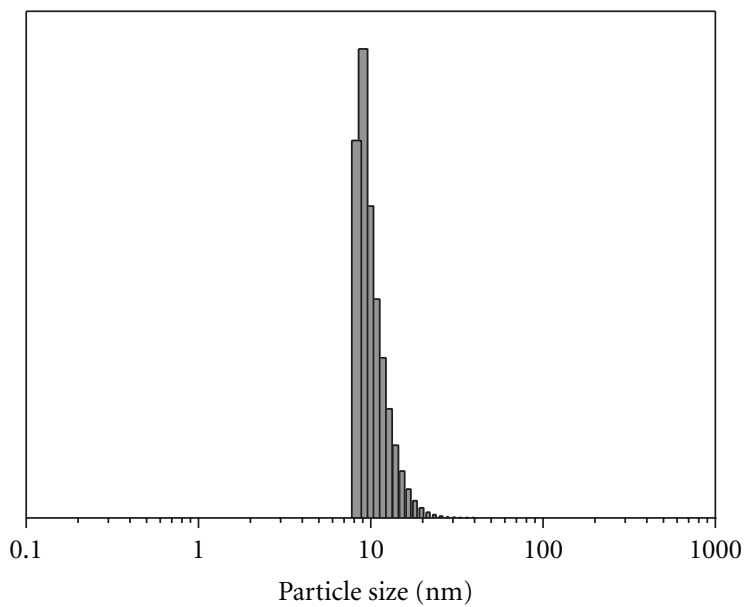

(c)

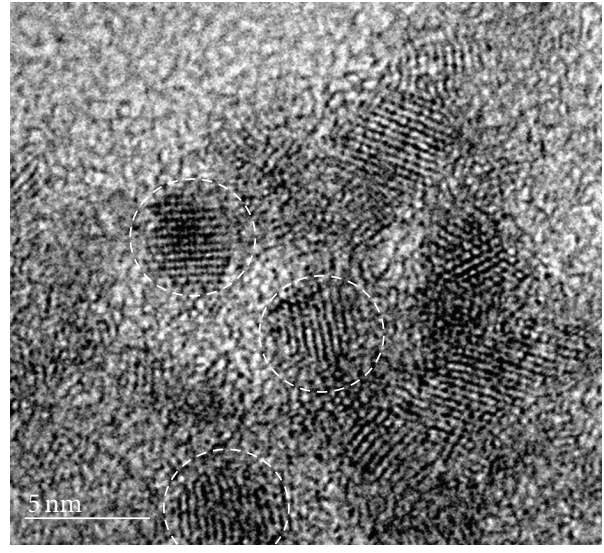

(b)

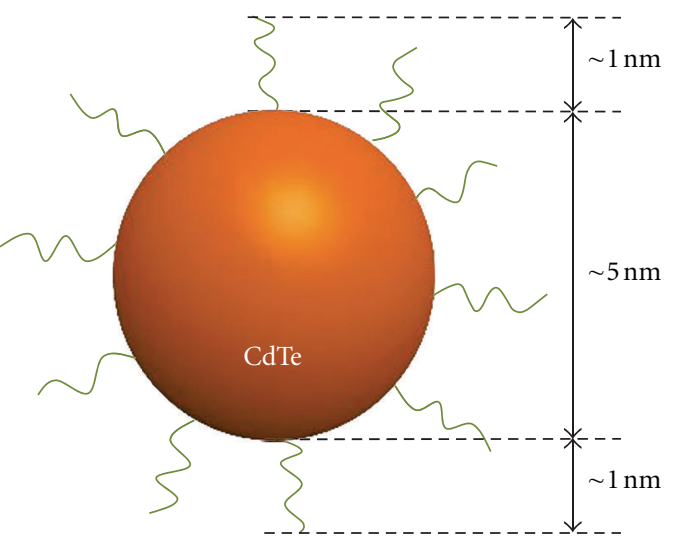

(d)

Figure 2: (a) Fluorescence images of dTFIL-capped CdTe QDs at different reaction times. All solutions were excited with a hand-held UV lamp. (b) TEM images of the dTFIL-capped QDs, taken from the aliquots at the reaction time of $12 \mathrm{~h}$. (c) DLS results of the dTFILcapped QD in aqueous solution, indicating a hydrodynamic size of $\sim 7 \mathrm{~nm}$, and (d) illustration of dTFIL-capped CdTe QD with estimated dimensions.

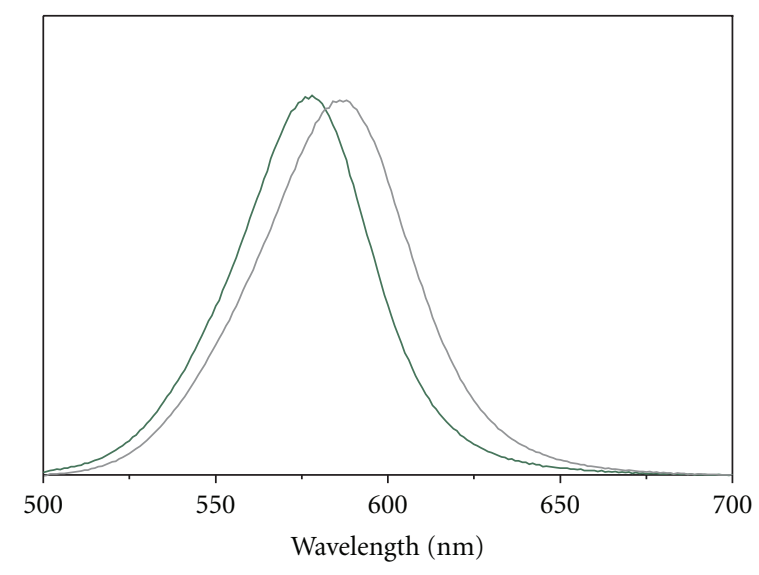

(a)

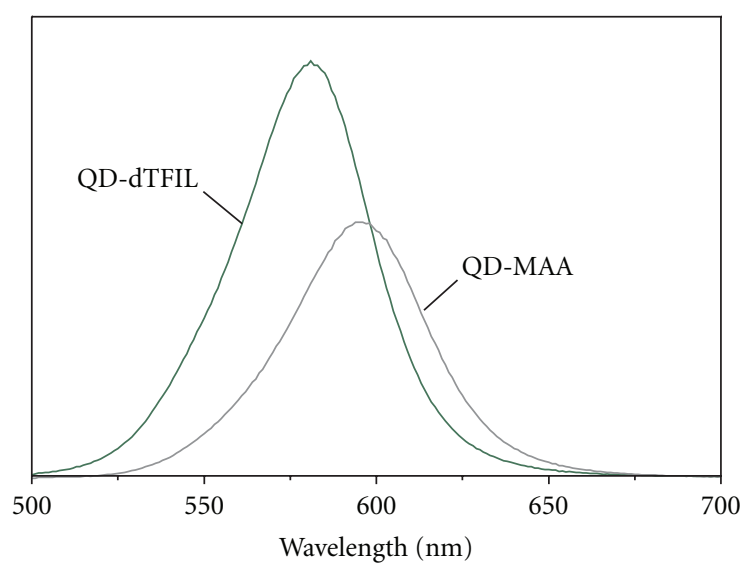

(b)

Figure 3: PL intensity of aqueous CdTe QDs (dTFIL- and MAA-capped QDs) as a function of the exposure time in ambient environment: (a) as-synthesized and (b) after 15 days. 


\section{Acknowledgments}

This work was supported by a Korea University Grant and InsCon Tech, Co. Ltd, Korea. S. Y. Choi and J. P. Shim contributed equally to the work.

\section{References}

[1] W. C. W. Chan and S. M. Nie, "Quantum dot bioconjugates for ultrasensitive nonisotopic detection," Science, vol. 281, no. 5385, pp. 2016-2018, 1998.

[2] M. J. Bruchez, M. Moronne, P. Gin, S. Weiss, and A. P. Alivisatos, "Semiconductor nanocrystals as fluorescent biological labels," Science, vol. 281, no. 5385, pp. 2013-2016, 1998.

[3] P. Alivisatos, "The use of nanocrystals in biological detection," Nature Biotechnology, vol. 22, no. 1, pp. 47-52, 2004.

[4] X. Peng, L. Manna, W. Yang et al., "Shape control of CdSe nanocrystals," Nature, vol. 404, no. 6773, pp. 59-61, 2000.

[5] C. B. Murray, D. J. Norris, and M. G. Bawendi, "Synthesis and characterization of nearly monodisperse CdE (E=sulfur, selenium, tellurium) semiconductor nanocrystallites," Journal of the American Chemical Society, vol. 115, no. 19, pp. 8706-8715, 1993.

[6] Z. A. Peng and X. Peng, "Formation of high-quality CdTe, CdSe, and CdS nanocrystals using $\mathrm{CdO}$ as precursor," Journal of the American Chemical Society, vol. 123, no. 1, pp. 183-184, 2001.

[7] L. Qu, Z. A. Peng, and X. Peng, "Alternative routes toward high quality CdSe nanocrystals," Nano Letters, vol. 1, no. 6, pp. 333$337,2001$.

[8] L. Qu and X. Peng, "Control of photoluminescence properties of CdSe nanocrystals in growth," Journal of the American Chemical Society, vol. 124, no. 9, pp. 2049-2055, 2002.

[9] I. L. Medintz, H. T. Uyeda, E. R. Goldman, and H. Mattoussi, "Quantum dot bioconjugates for imaging, labelling and sensing," Nature Materials, vol. 4, no. 6, pp. 435-446, 2005.

[10] N. Gaponik, I. L. Radtchenko, G. B. Sukhorukov, H. Weller, and A. L. Rogach, "Toward encoding combinatorial libraries: charge-driven microencapsulation of semiconductor nanocrystals luminescing in the visible and near IR," Advanced Materials, vol. 14, no. 12, pp. 879-882, 2002.

[11] M. Han, X. Gao, J. Z. Su, and S. Nie, "Quantum-dot-tagged microbeads for multiplexed optical coding of biomolecules," Nature Biotechnology, vol. 19, no. 7, pp. 631-635, 2001.

[12] X. Gao, Y. Cui, R. M. Levenson, L. W. K. Chung, and S. Nie, "In vivo cancer targeting and imaging with semiconductor quantum dots," Nature Biotechnology, vol. 22, no. 8, pp. 969976, 2004.

[13] T. Nann and P. Mulvaney, "Single quantum dots in spherical silica particles," Angewandte Chemie-International Edition, vol. 43, no. 40, pp. 5393-5396, 2004.

[14] B. Hardwick, W. Jackson, G. Wilson, and A. W.H. Mau, "Synthesis of tunable, highly luminescent QD-glasses through solgel processing," Advanced Materials, vol. 13, no. 12-13, pp. 985-988, 2001.

[15] P. Mulvaney, L. M. Liz-Marzán, M. Giersig, and T. Ung, "Silica encapsulation of quantum dots and metal clusters," Journal of Materials Chemistry, vol. 10, no. 6, pp. 1259-1270, 2000.

[16] S. T. Selvan, T. T. Tan, and J. Y. Ying, "Robust, non-cytotoxic, silica-coated CdSe quantum dots with efficient photoluminescence," Advanced Materials, vol. 17, no. 13, pp. 1620-1625, 2005.
[17] B. Dubertret, P. Skourides, D. J. Norris, V. Noireaux, A. H. Brivanlou, and A. Libchaber, "In vivo imaging of quantum dots encapsulated in phospholipid micelles," Science, vol. 298, no. 5599, pp. 1759-1762, 2002.

[18] H. Fan, E. W. Leve, C. Scullin et al., "Surfactant-assisted synthesis of water-soluble and biocompatible semiconductor quantum dot micelles," Nano Letters, vol. 5, no. 4, pp. 645648, 2005.

[19] W. Guo, J. J. Li, Y. A. Wang, and X. Peng, "Conjugation chemistry and bioapplications of semiconductor box nanocrystals prepared via dendrimer bridging," Chemistry of Materials, vol. 15, no. 16, pp. 3125-3133, 2003.

[20] X. S. Wang, T. E. Dykstra, M. R. Salvador, I. Manners, G. D. Scholes, and M. A. Winnik, "Surface passivation of luminescent colloidal quantum dots with poly(dimethylaminoethly methacrylate) through a ligand exchange process," Journal of the American Chemical Society, vol. 126, no. 25, pp. 7784-7785, 2004.

[21] J. M. Behrendt, M. Afzaal, L. M. Alexander et al., “Thiol-containing microspheres as polymeric ligands for the immobilisation of quantum dots," Journal of Materials Chemistry, vol. 19, no. 2, pp. 215-221, 2009.

[22] J. Aldana, N. Lavelle, Y. J. Wang, and X. G. Peng, "Size-dependent dissociation $\mathrm{pH}$ of thiolate ligands from cadmium chalcogenide nanocrystals," Journal of the American Chemical Society, vol. 127, no. 8, pp. 2496-2504, 2005.

[23] F. Pinaud, D. King, H. P. Moore, and S. Weiss, "Bioactivation and cell targeting of semiconductor CdSe/ZnS nanocrystals with phytochelatin-related peptides," Journal of the American Chemical Society, vol. 126, no. 19, pp. 6115-6123, 2004.

[24] D. V. Talapin, A. L. Rogach, I. Mekis et al., "Synthesis and surface modification of amino-stabilized CdSe, CdTe and InP nanocrystals," Colloids and Surfaces A, vol. 202, no. 2-3, pp. 145-154, 2002.

[25] A. L. Rogach, T. Franzl, T. A. Klar et al., "Aqueous synthesis of thiol-capped CdTe nanocrystals: state-of-the-art," Journal of Physical Chemistry C, vol. 111, no. 40, pp. 14628-14637, 2007.

[26] N. Gaponik, D. V. Talapin, A. L. Rogach et al., "Thiol-capping of CDTe nanocrystals: an alternative to organometallic synthetic routes," Journal of Physical Chemistry B, vol. 106, no. 29, pp. 7177-7185, 2002.

[27] D. V. Talapin, A. L. Rogach, E. V. Shevchenko, A. Kornowski, M. Haase, and H. Weller, "Dynamic distribution of growth rates within the ensembles of colloidal II-VI and III-V semiconductor nanocrystals as a factor governing their photoluminescence efficiency," Journal of the American Chemical Society, vol. 124, no. 20, pp. 5782-5790, 2002.

[28] J. Aldana, Y. A. Wang, and X. Peng, "Photochemical instability of CdSe nanocrystals coated by hydrophilic thiols," Journal of the American Chemical Society, vol. 123, no. 36, pp. 8844-8850, 2001.

[29] S. F. Wuister, I. Swart, F. van Driel, S. G. Hickey, and C. D. M. Donega, "Highly luminescent water-soluble CdTe quantum dots," Nano Letters, vol. 3, no. 4, pp. 503-507, 2003.

[30] H. Mattoussi, J. M. Mauro, E. R. Goldman et al., "Self-assembly of CdSe-ZnS quantum dot bioconjugates using an engineered recombinant protein," Journal of the American Chemical Society, vol. 122, no. 49, pp. 12142-12150, 2000.

[31] H. Itoh, K. Naka, and Y. Chujo, "Synthesis of gold nanoparticles modified with ionic liquid based on the imidazolium cation," Journal of the American Chemical Society, vol. 126, no. 10, pp. 3026-3027, 2004. 
[32] T. Y. Kim, W. J. Kim, S. H. Hong, J. E. Kim, and K. S. Suh, "Ionic-Liquid-Assisted Formation of Silver Nanowires," Angewandte Chemie-International Edition, vol. 121, no. 21, pp. 3864-3867, 2009.

[33] G. T. Wei, Z. Yang, C. Y. Lee, H. Y. Yang, and C. R. C. Wang, "Aqueous-organic phase transfer of gold nanoparticles and gold nanorods using an ionic liquid," Journal of the American Chemical Society, vol. 126, no. 16, pp. 5036-5037, 2004.

[34] T. Nakashima and T. Kawai, "Quantum dots-ionic liquid hybrids: efficient extraction of cationic CdTe nanocrystals into an ionic liquid," Chemical Communications, no. 12, pp. 1643$1645,2005$.

[35] T. Nakashima, T. Sakakibara, and T. Kawai, "Highly luminescent CdTe nanocrystal-polymer composites based on ionic liquid," Chemistry Letters, vol. 34, no. 10, pp. 1410-1411, 2005.

[36] S. Hohng and T. Ha, "Near-complete suppression of quantum dot blinking in ambient conditions," Journal of the American Chemical Society, vol. 126, no. 5, pp. 1324-1325, 2004. 

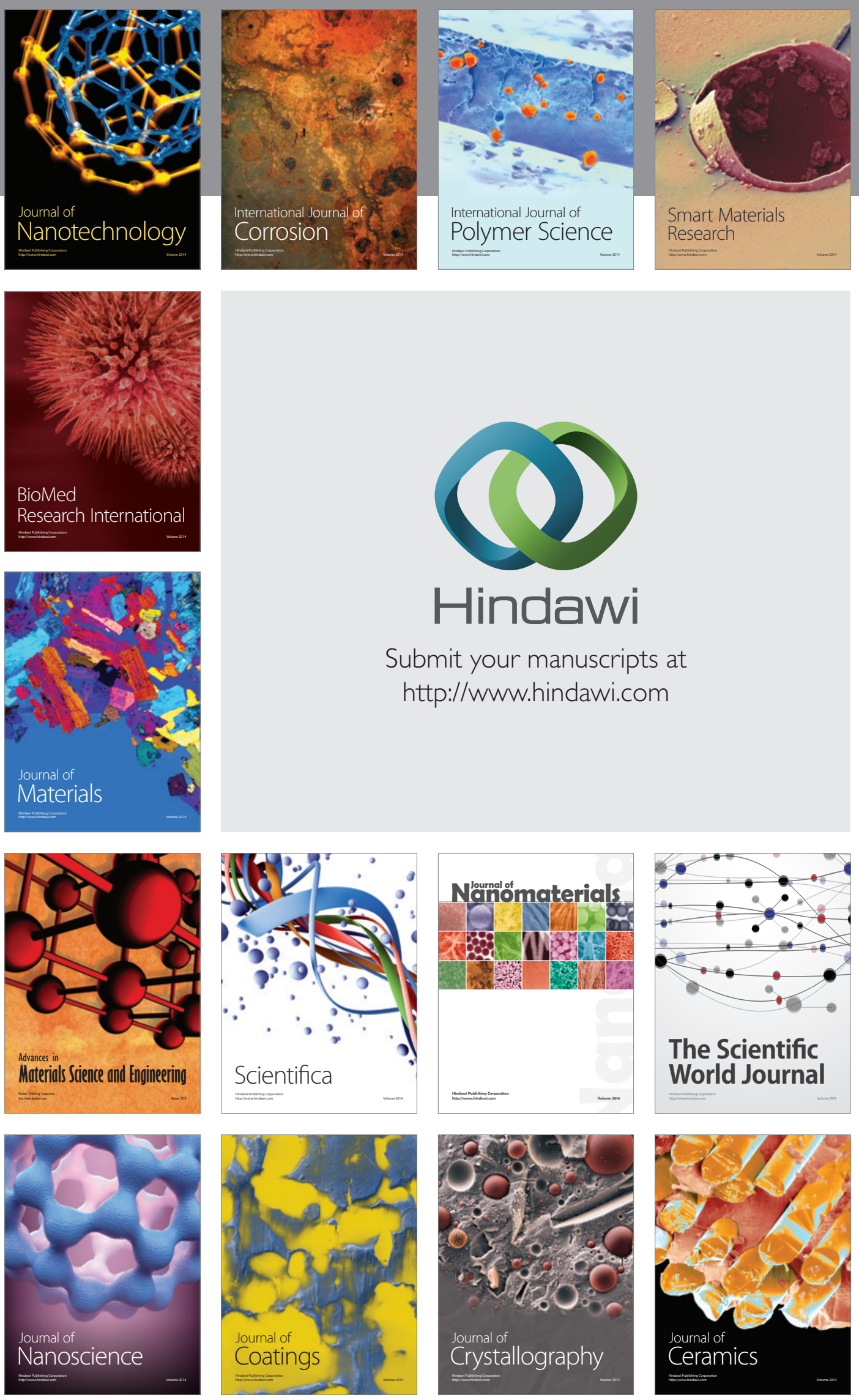

The Scientific World Journal

Submit your manuscripts at

http://www.hindawi.com

\section{World Journal}

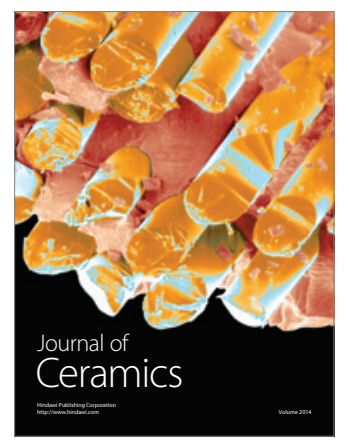

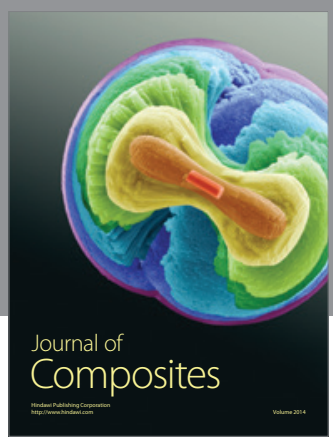
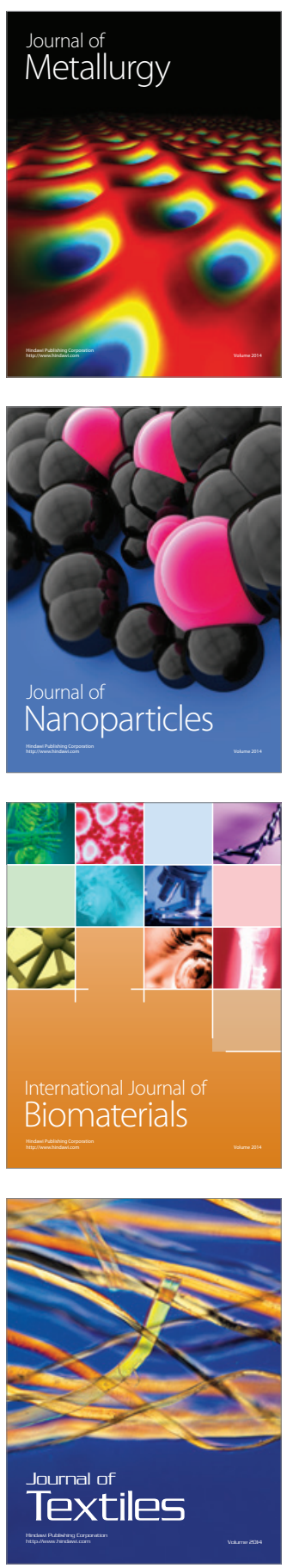